\title{
Screening for Novel LOX and SOD1 Variants in Keratoconus Patients from Brazil
}

\section{Diego Nery Benevides Gadelha', MD, DS; Alex Felipe Barbosa Feitosa ${ }^{1}$, BS; Rafaela Gomes da Silva ${ }^{1}$, BS Luana Talita Antunes ${ }^{1}$, MD; Matheus Cavalcanti Muniz ${ }^{1}$, MD; Matheus Alencar de Oliveira ${ }^{1}$, MD Dáfine de Oliveira Andrade ${ }^{1}$, BS; Nathalia Mayanna da Paz Silva', BS; Sebastião Cronemberger ${ }^{2}$, MD, DS Bruno Luiz Fonseca Schamber-Reis ${ }^{1}$, MS, DS}

${ }^{1}$ Department of Medical Genetics, School of Medical Sciences, UNIFACISA, Campina Grande, Paraíba, Brazil ${ }^{2}$ Medical School, University of Minas Gerais, Belo Horizonte, Brazil

ORCID:

Diego Nery Benevides Gadelha: https://orcid.org/0000-0003-3015-9904

Bruno Luiz Fonseca Schamber-Reis: https://orcid.org/0000-0002-7640-1463

\section{Abstract}

Purpose: To investigate the presence of the variants of lysyl oxygenase (LOX) and superoxide dismutase 1 (SOD1) genes in Brazilian patients with advanced keratoconus. Methods: Donor genomic DNA extracted from blood samples was screened for 5'UTR, exonic $L O X$, and SOD1 variants in a subset of 26 patients presenting with advanced keratoconus (KISA $>1000 \%$ and $\mathrm{I}-\mathrm{S}>2.0$ ) by Sanger sequencing. The impact of non-synonymous amino acid changes was evaluated by SIFT, PMUT, and PolyPhen algorithms. The Mutation Taster tool was used to evaluate the potential impact of formation of new donor and acceptor splice sites in the promoter region of affected volunteers carrying sequence variants. A 7-base SOD1 deletion (IVS2 + 50del7bp) previously associated with keratoconus was screened in 140 patients presenting classical keratoconus by gel fragment analysis, and positive samples were sequenced for confirmation.

Results: We found an unreported missense variant in LOX exon 6 in one heterozygous patient, leading to substitution of proline with threonine at residue 392 ( $p$. Thr392Pro) of $L O X$ protein sequence. This mutation was predicted to be potentially damaging to LOX protein. Another LOX variant, Arg158GIn, was also detected in another patient but predicted to be non-pathogenic. Two additional new polymorphisms in LOX 5'UTR region $(-116 \mathrm{C}>\mathrm{T}$ and $-58 \mathrm{C}>\mathrm{T})$ were found in two patients presenting with advanced keratoconus and were predicted to modulate or create donor/acceptor splice sites in $L O X$ transcripts. Additionally, SOD1 deletion was detected in one patient presenting with severe keratoconus, not in control samples.

Conclusion: We described three novel LOX polymorphisms identified for the first time in Brazilian patients with advanced keratoconus, as well as a previously described SOD1 deletion strongly associated with keratoconus. A possible role of these variants in modulating transcript levels in the cornea of affected individual requires further investigation.

Keywords: Keratoconus; Mutation; LOX; SOD1

J Ophthalmic Vis Res 2020; 15 (2): 138-148 
Correspondence to:

Bruno Luiz Fonseca Schamber-Reis, MS, DS. Department of Medical Genetics, School of Medical Sciences, UNIFACISA, Av. Senador Argemiro de Figueiredo, 1901, Bairro Itararé, Campina Grande, Paraiba 58411, Brazil. E-mail: bruno.reis@unifacisa.edu.br

Received: 11-03-2019 Accepted: 23-12-2019

$$
\text { Access this article online }
$$

Website:

https://knepublishing.com/index.php/JOVR

DOI:

10.18502/jovr.v15i2.6730

\section{INTRODUCTION}

Keratoplasty is the most frequent tissue transplantation in Brazil, comprising $60 \%$ of all organ and tissue transplantations in the country. ${ }^{[1]}$ Among these, around $50 \%$ of all performed keratoplasties are due to keratoconus (KC), which is characterized by corneal ectasia and stromal protrusion in a conical shape. Clinical signs of $\mathrm{KC}$ usually manifest first at puberty and in young adults leading to visual deterioration due to irregular astigmatism, myopia, and corneal scarring in about $20 \%$ of patients. ${ }^{[2,3]}$ Although KC manifests in only one eye in most patients, the disease can progress to bilaterality in severely affected individuals. ${ }^{[4]}$ Histologically, $\mathrm{KC}$ is characterized by impaired collagen secretion resulting from degeneration of keratocytes as well as by epithelial and stromal changes leading to disorganization of fibers involved in tissue resistance and stability. ${ }^{[5]} \mathrm{KC}$ incidence is estimated at $1 / 2,000$ individuals in the general population, with a prevalence of 50 to 230 cases $/ 100,000$ in Western countries. ${ }^{[6]}$ Diagnosis is usually based on qualitative corneal topography and quantitative videokeratography of posterior corneal surface confirmed by a KISA index $>100 \% .{ }^{[7]}$ Refractive error in $\mathrm{KC}$ can be corrected with glasses or contact lenses. About $20 \%$ of patients have more advanced disease, for which Ferrara intrastromal corneal ring segments (Ferrara rings) are recommended, along with penetrating keratoplasty in most cases. ${ }^{[6,8]}$

The etiology of $\mathrm{KC}$ is not completely understood. The disorder has been described as multifactorial and polygenic. ${ }^{[9-11]}$ Most cases are sporadic suggesting the role of environmental factors in susceptible individuals, including atopic factors, mechanical trauma, and ultraviolet (UV) light exposure, which may promote corneal thinning and tissue degradation. However, a strong association of isolated environmental factors with $\mathrm{KC}$ has not been effectively demonstrated. ${ }^{[4,10,12]}$ Twins $^{[13]}$ and family-based studies, ${ }^{[14]}$ candidate gene strategies, and genomic association studies have shown the influence of DNA variants on KC development. Many candidate genes regulating production or arrangement of collagen fibers, ${ }^{[15-17]}$ keratocyte proliferation/apoptosis, ${ }^{[12]}$ morphogenesis, and regulation of oxidative stress, ${ }^{[18,19]}$ as well as chromosomal loci bearing specific single nucleotide polymorphisms (SNPs) have been described in KC patients. The LOX gene, located at $5 q 23.1$, is among the most investigated genes in $K C .{ }^{[15,16,20]} L O X$ encodes a copper-dependent, oxido-deaminase lysyl oxidase enzyme, which plays a role in extracellular matrix maintenance by oxidizing lysine residues and promoting the formation of covalent cross-links of collagens and elastin, ${ }^{[16]}$ making them insoluble in the extracellular environment. ${ }^{[21]}$ Reduced $L O X$ activity has been detected in the cornea of patients with $\mathrm{KC}$, suggesting a significant role of this gene in the pathogenesis of disease. ${ }^{[15,22,23]}$ Two of the main missense mutations, Arg158GIn (rs1800449) and Pro159GIn (rs41407546), have been described in both Italian and Iranian populations ${ }^{[16,20]}$. A role of the Arg158GIn mutation in $\mathrm{KC}$ has been demonstrated in a genome-wide association study that also identified an SNP associated with the 5'UTR region. ${ }^{[20]}$ These data suggest a likely role of the LOX gene in the development of $\mathrm{KC}$. Another candidate gene is SOD1 (superoxide dismutase 1), which has a direct involvement in antioxidative processes associated with reactive oxygen species (ROS) elimination and reduction of oxidative stress that is increased in the corneal cells of patients with $K C .^{[24]}$ Located at 21q22.11, SOD1 encodes a copper and zincdependent cytoplasmic enzyme associated with

This is an open access journal, and articles are distributed under the terms of the Creative Commons Attribution-NonCommercial-ShareAlike 4.0 License, which allows others to remix, tweak, and build upon the work non-commercially, as long as appropriate credit is given and the new creations are licensed under the identical terms.

How to cite this article: Gadelha DNB, Feitosa AFB, da Silva RG, Antunes LT, Muniz MC, de Oliveira MA, Andrade DdO, da Paz Silva NM, Cronemberger $\mathrm{S}$, Schamber-Reis BLF. Screening for Novel LOX and SOD1 Variants in Keratoconus Patients from Brazil. J Ophthalmic Vis Res 2020;15:138-148. 
dismutation of ROS such as superoxide radicals. ${ }^{[25]}$ There is evidence of a correlation between SOD1 variations and the development of $\mathrm{KC}$, given the presence of high levels of oxidative stress markers and/or accumulation of these markers in the cornea of affected individuals. ${ }^{[26]}$ Several studies have described a heterozygous genomic 7-base deletion in the intron 2 of the SOD1 gene (IVS2 + 50del7bp) in the US population which significantly affected the conformation and function leading to an increase in oxidative stress in the cornea. ${ }^{[27-29]}$ Two sporadic carriers of this deletion were also detected in the Italian population, ${ }^{[30]}$ and nine in the Greek population. ${ }^{[2]}$ The involvement of SOD1 in other ocular diseases such as primary open-angle glaucoma has also been described. ${ }^{[31]}$

Although already well studied, ${ }^{[32,33]}$ the genetic basis of KC is still poorly understood. ${ }^{[34]}$ Despite the availability of data on the involvement of SOD1 and $L O X$ mutations in the development of $\mathrm{KC}$ in specific cohorts, little information is available regarding Brazilian patients. A single study, using a gene candidate approach, showed three nonsynonymous substitutions (Leu68His, Arg131Ser, and Asp105Glu) in VSX1 gene segregating with the phenotype in patients from the Northeast of Brazil who presented with sporadic KC, suggesting a role for this gene in KC development. ${ }^{[35]}$ However, no additional studies are available in Brazil regarding polymorphisms in other genes whose involvement in $\mathrm{KC}$ has already been described. The implication of SOD1 and $L O X$ mutations on $\mathrm{KC}$ development may be important risk factors for the disease and their involvement in disease pathogenesis depends on additional studies on different ethnicities. ${ }^{[25,33]}$ Considering that this pathology is considered a major public health issue in Brazil, the aim of this study was to investigate the presence of genetic variants in SOD1 and LOX genes in individuals affected by advanced KC.

\section{METHODS}

\section{Study Protocol and Participants}

The research protocol was approved by the Human Research Ethics Committee at Unifacisa (CAAE 98902918.6.0000.5175) as determined by Resolution 466/12 of the Brazilian National Health Council and the Declaration of Helsinki. All participants signed an informed consent form prior to their enrolment.

Volunteer participants were recruited at an ophthalmology outpatient clinic (UNIFACISA/Campina Grande) in the state of Paraiba, Brazil. The sample included residents of Campina Grande and neighboring cities (Lagoa Seca, Queimadas, Esperança and Massaranduba). At the time of enrolment, 10 $\mathrm{mL}$ of whole blood were collected for later DNA extraction and stored in a $-80^{\circ} \mathrm{C}$ freezer at the Unifacisa Medical Genetics Core Laboratory (NUGEM). Participants were included if they met minimal topographic criteria for the diagnosis of KC: KISA $>100 \%$ and inferior-superior asymmetry (I-S) ratio $>1.4$ diopters (D) in at least one eye. ${ }^{[4]}$ Diagnostic confirmation was based on keratometry, performed in an Eyetech CT2000 SLE topographer (Eyetech Equipment, São Paulo, Brazil) and Schwind Sirius Scheimpflug (Eye-tech-Solutions, GmbH\&Co. Kleinostheim, Germany) tomograph. Patients with other eye disorders (glaucoma or cataract) or those undergoing corneal transplantation were excluded.

Of the overall group consisting of 140 patients, 26 patients had KISA > 1000\% and $\mathrm{I}-\mathrm{S}>2.0$; these were included in an advanced KC subgroup. To maximize the chance of detecting the variables with the highest pathogenic potential, DNA sequencing for LOX gene was performed specifically for this subgroup. A control group of 50 healthy subjects was also screened.

\section{DNA Sequencing}

Genomic DNA was extracted from blood samples. All SOD1 and LOX gene exons were sequenced after amplification by polymerase chain reaction (PCR). For that, appropriate forward and reverse primers were used as previously described [29, 36, Supplementary Table 1]. The primers used for amplification of SOD1 exon 1 also spanned the proximal 5' untranslated region (UTR), corresponding to approximately 150 base pairs (bp) upstream from SOD1 start codon.

PCR was run in $25 \mu \mathrm{L}$ volumes containing 12.5 $\mu \mathrm{L}$ GoTaq Green Master Mix (Promega, USA), 5 pmol of each oligonucleotide primer, and $1 \mu \mathrm{L}$ resuspended DNA solution at an approximate concentration of $200 \mathrm{ng} / \mathrm{\mu L}$. Reactions were performed in a thermocycler as follows: $5 \mathrm{~min}$ at $95^{\circ} \mathrm{C}$, followed by 35 cycles $1 \mathrm{~min}$ at $95^{\circ} \mathrm{C}$ for DNA denaturation, $1 \mathrm{~min}$ for primer annealing, 
and $1 \mathrm{~min}$ at $72^{\circ} \mathrm{C}$ for extension), and a final 5 min extension step at $72^{\circ} \mathrm{C}$. Specificity and quality of the amplicons were assessed in agarose gel at $0.8 \%$ containing ethidium bromide $(0.5 \mu \mathrm{g} / \mathrm{mL})$. Fragments were visualized by UV light using a LPIX transilluminator (Loccus Biotecnologia, Brazil).

To sequence PCR products, amplified exon segments were purified using the Wizard SV Gel and PCR Clean-up System (Promega, USA). Purity was assessed using a Nano-volume spectrophotometer (NanoVue Plus, GE), considering a $260 \mathrm{~nm} / 280$ $\mathrm{nm}$ absorbance ratio of 1.7 to 2.0 as the purity standard. Each sequencing reaction $(7.5 \mu \mathrm{L}$ final volume) contained $10 \mathrm{ng}$ per $100 \mathrm{bp}$ of specific exons and 10 pmoles of each individual primer. Reactions were submitted to Myleus Biotechnology (Belo Horizonte/MG, Brazil) for Sanger sequencing on an ABI3130 platform. Analysis of the electropherograms was performed using Sequence Scanner 2 v.2.0 (Applied Biosystems, EUA) and Sequence Viewer v.7.0.2 (CLCBio, Denmark) software. Gene sequence readings were compared to ancestral SOD1 (ENSG00000142168) and LOX (ENSG00000113083) sequences downloaded from the Ensemble genome browser (www.ensembl. org). All variations detected in samples were reconfirmed by a new DNA extraction and sequencing.

To test for the presence of the intronic 7-base deletion IVS2 + 50del7bp (c.169+50delTAAACAG) in SOD1, samples were tested by PCR in $140 \mathrm{KC}$ positive patients and 120 controls, using previously described amplification conditions. ${ }^{[29]}$ Detection of this deletion in patients involved direct visualization of a $211 \mathrm{bp}$ amplicon in a $20 \times 20 \mathrm{~cm}$ PAGE (5\%) electrophoresis, followed by confirmatory DNA sequencing of positive samples.

\section{Prediction of Pathogenic Potential of Gene Variants}

To predict the impact of nonsynonymous substitutions in LOX protein variants, we used SIFT (http: //sift.jcvi.org/), ${ }^{[37]}$ PolyPhen2 (http://genetics.bwh. harvard.edu/pph2/), and PMUT (http://mmb.pcb. ub.es/PMut/) tools. ${ }^{[38]}$ These algorithms assigned scores (i.e., probability of the substitution being damaging) ranging from 0 to 1 . Scores are generated through comparison between the ancestral amino acid sequence and the variant sequence (missense mutation). In the SIFT platform, a score up to 0.5 indicates a potentially pathogenic variant, whereas higher scores indicate a benign substitution. Conversely, the PMUT and PolyPhen2 platforms use values close to zero indicating a benign variant, with values closer to 1 suggesting a pathogenic variant.

To predict the impact of 5'-UTR LOX polymorphisms as pathogenic or neutral, the web-based Mutation Taster application (www.mutationtaster. org) was used. PhyloP and phastCons tools were also used to verify the grade of conservation of SNPs. Briefly, phastCons values range from 0 to 1 and reflect the probability that each nucleotide belongs to a conserved regulatory element, based on multiple alignment of genome sequences of 46 different species, as well as alterations in neighboring nucleotides. Values closer to 1 indicate high residue conservation. For phyloP (values ranging from -14 to +6$)$, the same method is used without considering neighboring nucleotides. Positive values are attributed to conserved sites. Additionally, the application predicts the expected impact of altering or creating non-canonical splice sites (including those detected in the 5'-UTR region of the gene) using an integrated version of the NNSplice software. Changes in typical splice sites may become stronger or weaker. New splices are indicated by a confidence score higher than 0.3. Information is also provided on the genomic position of the splice site, the prediction scores for reference and mutated sites, and a short sequence indicating the intron/exon border.

In addition, to assess the amino acid conservation, primary amino acid sequences coded for human SOD1 and LOX genes were aligned to multiple ortholog gene sequences in phylogenetically close organisms downloaded from Ensembl (www. ensembl.org), using the ClustalW Omega software (http://www.ebi.ac.uk/Tools/msa/clustalo/).

\section{RESULTS}

Of the 26 patients with advanced $\mathrm{KC}$ selected for the present study, 16 (61.5\%) were female. Mean age was 28.5 years $(S D \pm 10.6)$, and mean KISA\% index was $921.5( \pm 1153.17)$ for the right eye and 1,451.5 ( \pm $607.6)$ for the left eye. Mean I-S was $6.60 \mathrm{D}( \pm 3.13)$ for the right eye and 6.83D $( \pm 3.35$ ) for the left eye. Topography data are summarized in Table 1.

The sequencing of $L O X$ coding region revealed two SNPs. The first variant is a cytosine to thymine transition at position 773 (c.773 C > T) [Figure 1A], 
Table 1. Mean KISA and I-S indexes in Brazilian patients with keratoconus

\begin{tabular}{|c|c|c|c|c|}
\hline \multirow[t]{2}{*}{ Eye } & \multicolumn{2}{|c|}{ KISA (\%) } & \multicolumn{2}{|c|}{ I-S } \\
\hline & Mean & SD & Mean & SD \\
\hline Right & 921.52 & 607.6 & 6.6 & 3.13 \\
\hline Left & $1,451.48$ & 1,153.17 & 6.83 & 3.35 \\
\hline
\end{tabular}

KISA, keratoconus percentage index; I-S, inferior-superior value; SD, standard deviation

Table 2. Predicted variant impact on LOX protein conformation analyzed by PMUT, SIFT, and PolyPhen2 algorithms. Allelic frequencies are indicated.

\begin{tabular}{lcccc}
\hline Residue & PMUT & PolyPhen2 & SIFT & TGP frequency \\
\hline R158Q & 0.11 & 0.000 & 0.21 & 0.157 (16\%) \\
T392P & 0.68 & 0.087 & 0.02 & ND
\end{tabular}

TGP, 1000 Genome project; ND, not described

Table 3. Mutation Taster analysis of SOD1 promoter nucleotide variations

\begin{tabular}{|c|c|c|c|c|c|c|}
\hline Variant & Effect & WT score & Variant score & Position & phyloP & phastCons \\
\hline$-58 \mathrm{C}>\mathrm{T}$ & Acc increased & 0.43 & 0.52 & g.90 & 0.216 & 0.015 \\
\hline$-58 \mathrm{C}>\mathrm{T}$ & Acc increased & 0.24 & 0.32 & g.97 & 0.216 & 0.015 \\
\hline$-58 \mathrm{C}>\mathrm{T}$ & Donor gained & NA & 0.38 & g.84 & 0.216 & 0.015 \\
\hline$(-116 \mathrm{C}>\mathrm{T})$ & Acceptor gained & NA & 0.32 & g.44 & 1.383 & 0.058 \\
\hline$-58 \mathrm{C}>\mathrm{T}$ & Acc increased & 0.43 & 0.52 & g.90 & 0.216 & 0.015 \\
\hline$-58 \mathrm{C}>\mathrm{T}$ & Acc increased & 0.24 & 0.32 & g.97 & 0.216 & 0.015 \\
\hline$-58 C>T$ & Donor gained & NA & 0.38 & g.84 & 0.216 & 0.015 \\
\hline$(-116 \mathrm{C}>\mathrm{T})$ & Acceptor gained & NA & 0.32 & g.44 & 1.383 & 0.058 \\
\hline
\end{tabular}

Table 4. Supporting Material - PCR Primers and annealing conditions used in this work

\begin{tabular}{|c|c|c|c|c|}
\hline Primer & Forward (5'-3') & Reverse (5'-3') & Tf (bp) & $\operatorname{Tm}\left({ }^{\circ} \mathrm{C}\right)$ \\
\hline LOX - P1a & GAGACTGAGATACCCGTGCT & AGCGGTGACTCCAGATGA & 474 & 58 \\
\hline LOX - P1b & TCACAGTACCAGCCTCAGC & ATAGCTGGGGACCAGGTG & 500 & 60 \\
\hline LOX-P2 & TTTTCACATTGCTTTGCAGT & GCTCTTGTCCСАCTTCCTAA & 398 & 58 \\
\hline LOX - P3 & TAGTTGGGAAAGGAGGATTG & GCAATTTTCTCCCTTCAGGT & 355 & 58 \\
\hline LOX - P4 & GACTTATGTCCTGGGGAAAA & GATAAAAATGTGTGTGCTCTTCA & 441 & 58 \\
\hline LOX - P5 & GGAGGTGCTATAAGGCTGAG & TTGCTTCCAATACCATGATT & 370 & 58 \\
\hline LOX - P6 & TTCAGGGGAAAATATGCAGT & TGCTTACAAGAAAGCTGCTG & 394 & 58 \\
\hline LOX - P7 & CTTAGGTGGAGGGAAACTGT & AAGTCATTTTGGCTCATTCA & 485 & 58 \\
\hline SOD1 - P1 & CTCCACATTTCGGGGTTCT & ACCCGCTCCTAGCAAAGGT & 450 & 58 \\
\hline SOD1 - P2 & ССАTСТСССТTTTGAGGACA & CGACAGAGCAAGACCCTTTC & 426 & 58 \\
\hline SOD1 - P3 & TGATGCAGGTCAGCACTTTC & AAAAGCATTCCAGCATTTGG & 344 & 58 \\
\hline SOD1 - P4 & ССАТСTTTСТTCCCAGAGCA & GAAACCGCGACTAACAATCAA & 386 & 58 \\
\hline SOD1 - P5 & TTTGGGTATTGTTGGGAGGA & TCTGTTCCACTGAAGCTGTTT & 675 & 59 \\
\hline SOD1 del & CAGAAACTCTCTCCAАСTTTGC & GAGGGGTTTTAACGTTTAGGG & 218 & 59 \\
\hline
\end{tabular}

PCR, polymerase chain reaction 
observed in three patients - two heterozygotes $(C / T)$ and one homozygote $(T / T)$. This variant leads to replacement of arginine with glutamine at residue 158 (p. Arg158GIn) of the primary LOX amino acid sequence. The second variant is an adenine to thymine substitution at position 1474 (c.1474T > A) of LOX exon 6 [Figure 1B]. This variant leads to a threonine to proline substitution at residue 392 ( $p$. Thr392Pro) of the primary LOX protein sequence. Thr392Pro is a previously unreported mutation of the LOX gene. None of these variants were found in control samples.

The assessment of the Thr392Pro mutation using the PMUT and PolyPhen platforms yielded scores of 0.68 and 0.087 , respectively, with $85 \%$ probability of pathogenicity [Table 2]. For the Arg158GIn variant, the PMUT score was 0.11, indicating a 95\% likelihood of this being a neutral mutation, which was confirmed by a low PolyPhen score. The results obtained with SIFT analysis produced scores of 0.02 and 0.21 for Arg158GIn and Thr392Pro, respectively, confirming a deleterious effect of Thr392Pro and a neutral impact of Arg158GIn.

Regarding the comparison with ancestral residues to determine amino acid conservation across different species through ClustalW Omega alignment, the two amino acids were found to be relatively conserved. Threonine at position 392 is greatly conserved in hominids, but not in more phylogenetically distant species [Figure 2].

SOD1 intronic 7-base deletion was detected in one patient [Figure 3A]. The patient was diagnosed with advanced $\mathrm{KC}$, presenting KISA values of 4,083 and 3,574 diopters and I-S values of 8,14 and 9,92 , for right and left eyes, respectively. This variant was not detected in any of the non-affected individuals. The sequencing of this region in the carrier showed an electropherogram pattern that suggests a concatenated overlapping of the wildtype and deleted alleles, a typical pattern observed in individuals who are heterozygote for deletion [Figure 3B].

In addition, we observed the presence of two base polymorphisms at the untranslated 5' region (5'-UTR) of SOD1 in two affected individuals. The two variants involved replacement of thymine with cytosine, one at position $-116(-116 \mathrm{C}>\mathrm{T})$ and the second at position $-58(-58 \mathrm{C}>\mathrm{T})$, both located at the SOD1 promoter region. Electropherograms for these variants showed heterozygous point mutations in both patients [Figure 4]. Variant $58 \mathrm{C}>\mathrm{T}$ had already been described in the dbSNP (rs906695375) databank, but not in 1000 Genomes. In the present work, this variant was detected in a proband with KISA score of 1,294\% and I-S of 4.68 in the right eye and KISA of 2,592\% and I-S score of 7.24 in the left eye. No other variants were found in SOD1 coding region in the 26 patients analyzed. The alignment of the human SOD1 promoter region sequence with that of other hominids show conservation of these residues over evolution [Figure 5].

An analysis of the impact of variants in the SOD1 gene promoter region showed a significant conservation score $(0.216)$ with phyloP analysis for the $58 \mathrm{C}>\mathrm{T}$ variant, as well as for the upstream (0.5) and downstream (1.771) flanking region phastCons analysis, which also showed significance for this variant, with values slightly higher than zero [Table 3]. A positive modulation by variant $-58 \mathrm{C}>\mathrm{T}$ of the splice acceptor sites predicted at positions 90 and 97 of the gene, with scores of 0.52 and 0.32 , respectively, was suggested. In addition, the analysis suggests the creation of a new ectopic splice donor site at position 84 , with a score of 0.38 . Analysis of variant $-116 \mathrm{C}>\mathrm{T}$ showed a new splice acceptor site at position 44 , with a score of 0.32. Significant conservation scores were also observed for phyloP (1.383) and phastCons (0.058).

\section{DISCUSSION}

Cornea has been the most transplanted tissue in Brazil since the late 1990s, with KC among the main etiologies. ${ }^{[39,40]}$ Molecular and linkage studies have suggested multiple candidate genes that might underlie the development of $\mathrm{KC} .^{[32]}$ In the present work, we found two nonsynonymous mutations in LOX, namely Arg158GIn and Thr392Pro, and an intronic SOD1 deletion previously associated with $\mathrm{KC}$ development. Variant Thr392Pro in the LOX gene is a novel missense mutation that has not been previously described; this mutation was found in 1 out of 26 patients with advanced $\mathrm{KC}$. The scores obtained with computational algorithms suggest a deleterious impact of this substitution on protein stability resulting from the replacement of threonine (aliphatic open side chain) with proline. Proline is an amino acid with non-polar side chain, therefore not capable of ionization and hydrogen bonding, and featuring a 


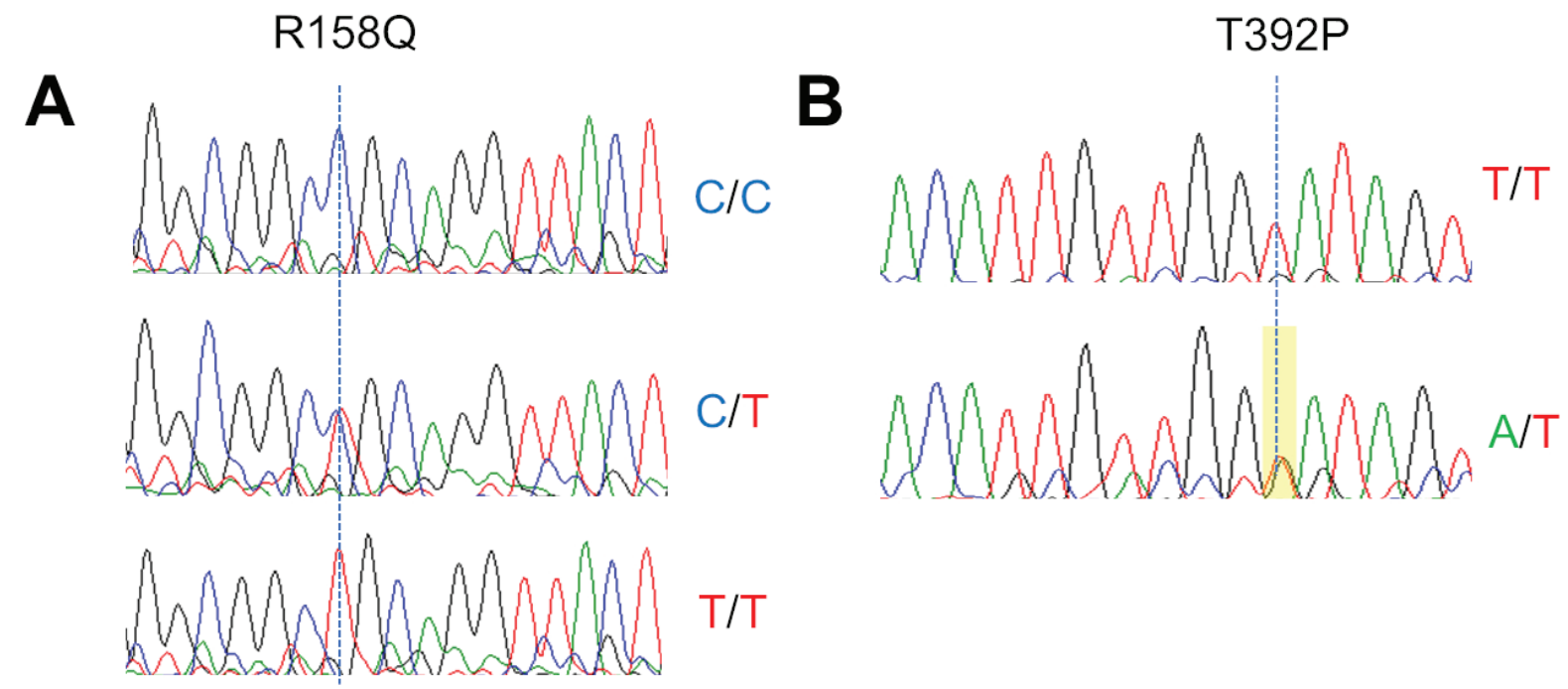

Figure 1. Electropherograms showing R158Q (c.773 C > T) (A) and T392P (c.1474T > A) (B) variants. Genotypes are indicated, and dotted vertical lines indicate peak location for each alteration. Sequencing of T392P variant was obtained using reverse primer.

158 . . . TAPGEVPALSNLR . . SYLVPESDYTNNVVRCDIR . . . Homo sapiens Mus musculus Pan troglodytes Gorillagorilla Bos taurus Felis catus
. . . TASPQPPQLSNLR . . . SYLVPESDYTNNVVRCDIR . . . . . TAPGDVPALSNLQ . . . SYLVPESDYTNNVVRCDIR . . . . . TAPGDVPALSNLQ . . SYLVPESDYTNNVVRCDIR . . . . . TAPGEVPTLSNLR . . . SYLVPESDYSNNVVRCEIR . . . . . TEPGERPALSNLR . . SYLVPESDYSNNVVRCEIR . .

Figure 2. Conservation of LOX primary amino acid sequence in several species. Positions of residues R158 and T392 relative to Homo sapiens LOX protein are indicated.

secondary rather than a primary amino group. This suggests that the substitution may possibly affect protein folding and compromise cellular function. In addition, threonine was conserved in hominids, which supports the notion that this residue is important for normal LOX function. Nevertheless, the non-conserved amino acid in Felis catus and Bos taurus is a serine, which presents a side chain with similar biochemical properties (both containing aliphatic hydroxyl groups), indicating an essential role in the secondary LOX structure of all species considered.

We found the missense Arg158GIn variant in LOX gene, detected in 3 of the 26 patients analyzed, with one being homozygous and two heterozygous for this mutation. This substitution has also been described (rs1800449) in other ethnic groups. ${ }^{[16,20]}$ However, a meta-analysis did not find sufficient evidence in the literature to associate this SNP with the development of $\mathrm{KC} .^{[15]}$ In fact, in silico assessments performed with PMUT, SIFT, and PolyPhen2 algorithms produced scores indicating this as a neutral, non-pathogenic substitution. This finding is confirmed by the high frequency of the T allele, found in $16 \%$ of the world population according to the 1000 Genome Project database. In addition, the glutamine for arginine (both of which have open chains of similar size) substitution is welltolerated because of the similar physicochemical characteristics of these amino acids and does not substantially interfere with $L O X$ protein folding. The alignment of $L O X$ sequences of phylogenetically close species also revealed non-conservation of this arginine. Therefore, the present findings suggest low impact of the Arg158GIn variant on LOX function. 


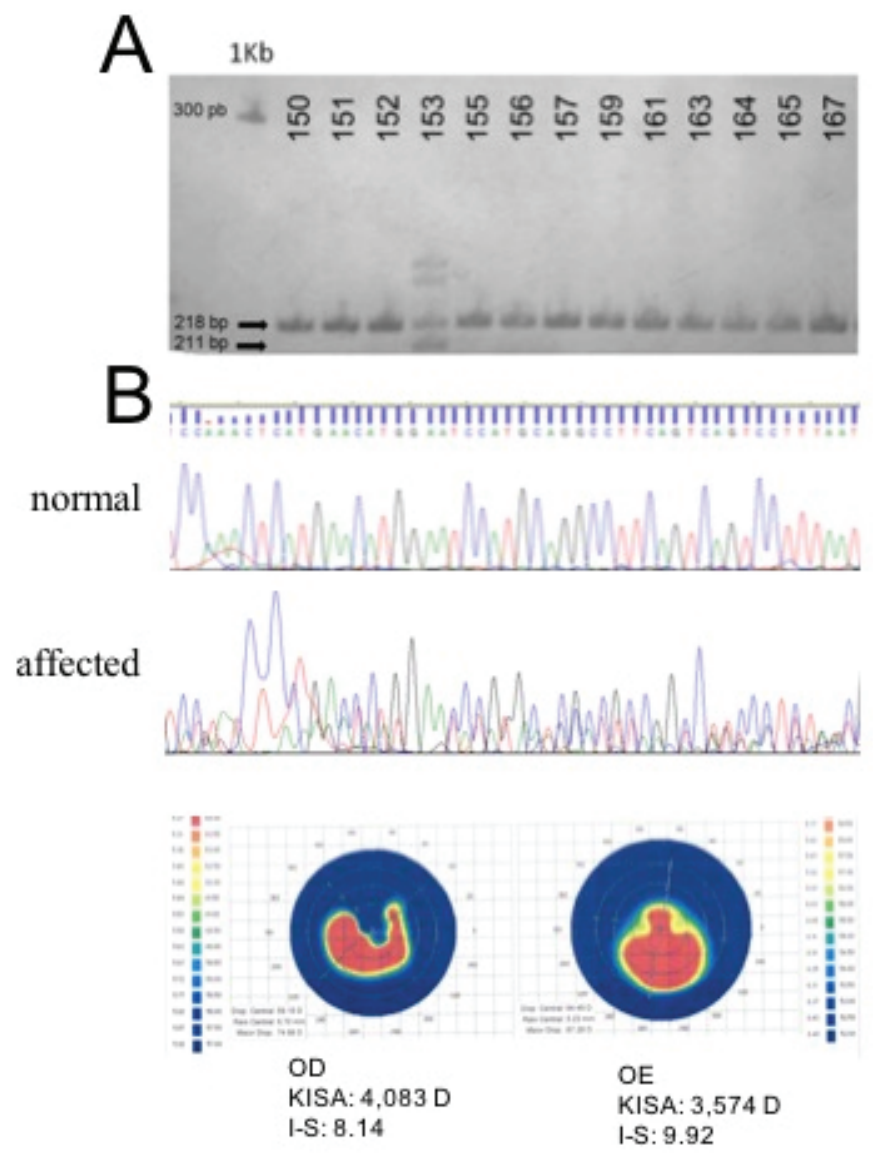

Figure 3. Detection of the IVS2 + 50del7bp deletion in SOD1 gene in one patient affected with advanced keratoconus. (A) PAGE electrophoresis showing a subset of patients tested for the deletion (numbers indicated above). Amplicons of 218 pb (normal) and $211 \mathrm{pb}$ (deleted) fragments are indicated by black arrows. A $1 \mathrm{~kb}$ DNA ladder shows the 300 pb reference fragment (smaller fragments are not shown). (B) Electropherograms of the deletion region from normal and affected patients. (C) Corneal topographies of KC patient carrying the SOD1 deletion. $\mathrm{PB}$, base pairs; KB, kilobases; OD, right eye; OE, left eye.

For the first time, we identified the IVS2 + 50 del7bp deletion in SOD1 gene in the Brazilian population. This variant was detected in 1 patient with severe $\mathrm{KC}$ out of $140 \mathrm{KC}$ affected volunteers, which was absent in 120 healthy controls. The literature has described significant association of this deletion with $\mathrm{KC}$ development both in familial and sporadic cases of various ethnicities. A study conducted by Udar et al reported a haplotypeindependent segregation of this deletion in two non-related American families presenting an autosomal dominant form of $\mathrm{KC}$. ${ }^{[27]}$ This finding suggests a likely autonomous effect of SOD1 IVS2 + 50 del7bp on KC pathogenesis. An mRNA analysis of SOD1 carrying this deletion showed, in addition of the wild-type transcript, two splice variants lacking exon 2, or both exon 2 and 3 simultaneously, which exclude SOD1 protein active site and lead to a loss of function protein. ${ }^{[27]}$ Another study with 33 Greek patients found that homozygote carriers for this deletion were significantly overrepresented among $\mathrm{KC}$ patients compared to healthy subjects. ${ }^{[29]}$ We also verified a similar frequency of IVS2 + 50del7bp allele found with other studies. ${ }^{[30]}$ We believe that this specific SOD1 deletion, yet with a low frequency in all cohorts studied, reinforces IVS2 + 50del7bp deletion as a key genetic alteration highly associated with $\mathrm{KC}$ in different populations.

We also detected two SNPs in the untranslated 5 ' region of SOD1, both characterized by replacements of cytosine with thymine at positions -58 and -116 in two different patients. There have been no reports in the literature of any of the two variants described in the present work. In silico analysis showed scores indicating increased activity of 


\section{A}

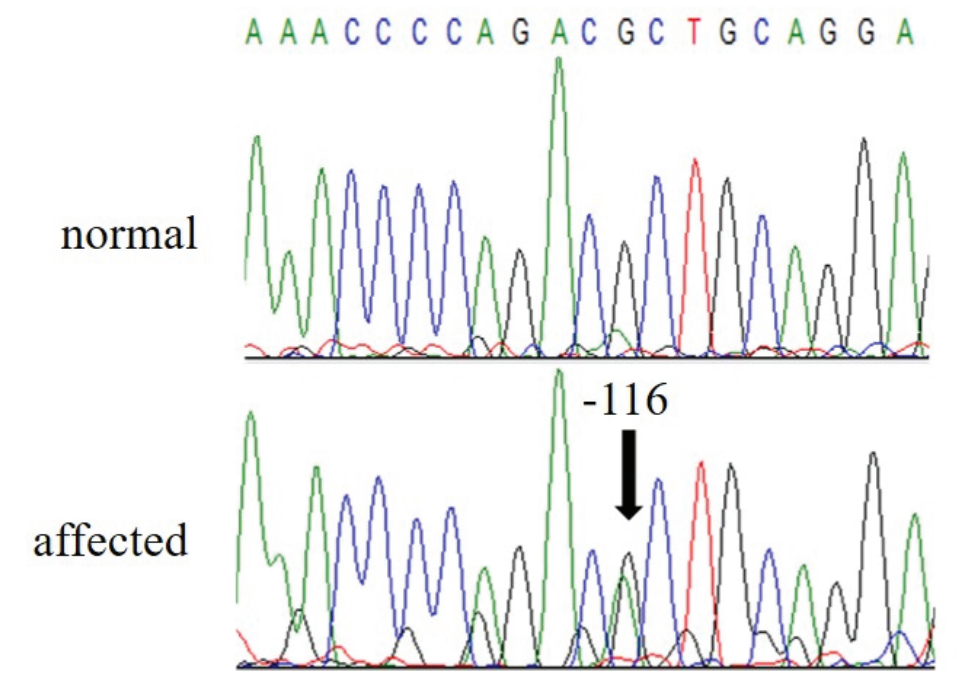

B


Figure 4. Electropherograms showing 5'UTR polymorphisms located at positions $-116 \mathrm{C}>\mathrm{T}(\mathrm{A})$ and $-58 \mathrm{C}>\mathrm{T}(\mathrm{B})$ relative to SOD1 ATG start site. Sequencing was performed using reverse primer.

$$
\begin{aligned}
& -116 \\
& \text { Homo sapiens ...GCGGAGGTCTGGCCTA. . TTGCGTCGTAGTCTCCTGCAG... } \\
& \text { Gorilla gorilla ...GCGGAGGTCCGGCCTA. . TTGCGGCGTAGTCTCCTGCAG. . . } \\
& \text { Pan troglodytes ...GCGGAGGTCTGGCCTA... TTGCGTCGTAGTCTCCTGCAG... } \\
& \text { Macaca mulatta ...GCGGAGGTCCGGCCTA. . TTGCGGCGTAGTCTCCTGCAG... } \\
& \text { Nomascus leucogenys ...GGGGAGGTCCGGCCTA... TTGCGGCGTAGTCTCCTGCAG... }
\end{aligned}
$$

Figure 5. DNA sequence alignment of SOD15'UTR sequences from different species. Conserved positions of residues -116 and -58 relative to Homo sapiens sequence are indicated.

splice acceptors in the presence of variant $-58 \mathrm{C}$ $>$ T. In addition, these scores also showed high probability of these variations having a pathological impact on SOD1 activity because of the creation of donor $(-58 \mathrm{C}>\mathrm{T})$ and acceptor $(-116 \mathrm{C}>\mathrm{T})$ splice sites. This is a noteworthy finding, since alterations in the SOD1 promoter region sequence may cause a decrease in protein expression, as shown for other disorders. ${ }^{[41,42]}$ The SOD1 protein neutralizes excess ROS in the cell, and ROS levels are increased in patients with $\mathrm{KC} .^{[43-45]}$ Low levels of SOD1 enzyme can also result from gene mutations. ${ }^{[28]}$ It is possible that these variants may be related to changes in the function of this gene in patients with $\mathrm{KC}$, considering that these are highly conserved residues and the predicted splice sites may influence the normal processing points at the exon-intron boundaries in the gene. We believe that these 5'-UTR variants may modulate SOD1 gene expression in KC patients, although additional in vitro studies involving cloning of the SOD1 gene, with a focus on the variants described in the present study and analysis of the impact of these variants on transcription rates, are essential to confirm the involvement of these polymorphisms in the pathophysiology of KC.

In conclusion, we report a novel Thr392Pro with potential damaging effect to $L O X$ protein in a Brazilian patient presenting advanced $\mathrm{KC}$, as well as a previously described Arg158GIn variant. We also detected a previously KC associated SOD1 IVS2 + 50del7bp deletion in another patient with 
severe KC, and two SNPs located in SOD1 5'UTR with still unclear involvement in KC pathogenesis. SOD1 and $L O X$ variants found in Brazilian unrelated $\mathrm{KC}$ patients suggests a genetic contribution to disease onset and progression, although further studies will be key to validate their impact on gene transcription and protein function. In addition, variant screening in larger samples will be essential to evaluate the real contribution of these polymorphisms to $\mathrm{KC}$ pathophysiology in Brazilian population.

\section{Acknowledgements}

The authors are grateful to Iracema Freitas da Silva for technical support and Fabio Mendes da Silva for blood sampling and topography imaging. The equipment and reagents acquisition were funded by CESED/UNIFACISA institutional resources.

\section{Financial Support and Sponsorship}

Nil.

\section{Conflicts of Interest}

There are no conflicts of interest.

\section{REFERENCES}

1. ABTO - Brazilian Association of Organ and Tissue Transplantation. Report on performed transplants - Jan/Dec 2018 [Internet]; 2019. Available from: abto.org.br.

2. Lechner J, Bae HA, Guduric-Fuchs J, Rice A, Govindarajan G, Siddiqui S, et al. Mutational analysis of MIR184 in sporadic keratoconus and myopia. Invest Ophthalmol Vis Sci 2013;54:5266-5272.

3. Moussa S, Grabner G, Ruckhofer J, Dietrich M, Reitsamer $\mathrm{H}$. Genetics in keratoconus - What is new? Open Ophthalmol J 2017;11:201-210.

4. Rabinowitz YS. Keratoconus. Surv Ophthalmol 1998;42:297-319.

5. de Araujo AL. Corneal stem cells and tissue engineering: current advances and future perspectives. World J Stem Cells 2015;7:806.

6. Gordon-Shaag A, Millodot M, Shneor E, Liu Y. The genetic and environmental factors for keratoconus. Biomed Res Int 2015;2015:24-32.

7. Gordon-Shaag A, Millodot M, Kaiserman I, Sela T, Itzhaki GB, Zerbib Y, et al. Risk factors for keratoconus in Israel: a case-control study. Ophtalmic Physiol Opt 2015;35:673681.

8. Vazirani J, Basu S. Keratoconus: current perspectives. Clin Ophthalmol 2013;7:2019-2030.
9. Sugar J, Macsay MS. What causes keratoconus? Cornea 2012;31:716-719.

10. Davidson AE, Hayes S, Hardcastle AJ, Tuft SJ. The pathogenesis of keratoconus. Eye 2014;28:189-195.

11. Galvis V, Sherwin T, Tello A, Merayo J, Barrera R, Acera A. Keratoconus: an inflammatory disorder? Eye 2015;29:843-859.

12. Wang $Y$, Rabinowitz YS, Rotter JI, Yang H. Genetic epidemiological study of keratoconus: evidence for major gene determination. Am J Med Genet 2000;93:403-409.

13. Tuft SJ, Hassan H, George S, Frazer DG, Willoughby CE, Liskova P. Keratoconus in 18 pairs of twins. Acta Ophthalmol 2012;90:482-486.

14. Burdon KP, Vincent AL. Insights into keratoconus from a genetic perspective. Clin Exp Optom 2013;96:146-154.

15. Zhang J, Zhang L, Hong J, Wu D, Xu J. Association of common variants in $L O X$ with keratoconus: a metaanalysis. PLOS ONE 2015;10:e0145815.

16. Hasanian-Langroudi F, Saravani R, Validad M-H, Bahari G, Yari D. Association of lysyl oxidase (LOX) polymorphisms with the risk of keratoconus in an Iranian population. Ophthalmic Genet 2015;36:309-314.

17. Saravani R, Farzaneh Hasanian-Langroudi M-HVDYGB, Mahmood Faramarzi M, Khateri M, Bahadoram S. Evaluation of possible relationship between COL4A4 gene polymorphisms and risk of keratoconus. Cornea 2015;34:318322.

18. Wojcik KA, Kaminska A, Blasiak J, Szaflik J, Szaflik JP. Oxidative stress in the pathogenesis of keratoconus and Fuchs endothelial corneal dystrophy. Int J Mol Sci 2013;14:19294-19308.

19. Vallabh NA, Romano V, Willoughby CE. Mitochondrial dysfunction and oxidative stress in corneal disease. Mitochondrion [Internet] 2017;36:103-113. Available from: http: //dx.doi.org/10.1016/j.mito.2017.05.009.

20. Bykhovskaya Y, Li X, Epifantseva I, Haritunians T, Siscovick $D$, Aldave A, et al. Variation in the lysyl oxidase (LOX) gene is associated with keratoconus in family-based and case-control studies. Investig Ophthalmol Vis Sci 2012;53:4152-4157.

21. Lucero HA, Kagan HM. Lysyl oxidase: an oxidative enzyme and effector of cell function. Cell Mol Life Sci 2006;63:2304-2316.

22. Dudakova L, Jirsova K. The impairment of lysyl oxidase in keratoconus and in keratoconus-associated disorders. $J$ Neural Transm 2013;120:977-982.

23. Shetty R, Sathyanarayanamoorthy A, Ramachandra RA, Arora V, Ghosh A, Srivatsa PR, et al. Attenuation of lysyl oxidase and collagen gene expression in keratoconus patient corneal epithelium corresponds to disease severity. Mol Vis 2015;21:12-25.

24. Behndig A, Karlsson K, Johansson BO, Brännström T, Marklund SL. Superoxide dismutase isoenzymes in the normal and diseased human cornea. Investig Ophthalmol Vis Sci 2001;42:2293-2296.

25. Wheeler J, Hauser M, Afshari N, Allingham RR, Liu Y. The genetics of keratoconus: a review. Reprod Syst Sex Disord Curr Res 2012;6:1-19.

26. Atilano SR, Coskun P, Chwa M, Jordan N, Reddy V, Le $\mathrm{K}$, et al. Accumulation of mitochondrial DNA damage in keratoconus corneas. Investig Ophthalmol Vis Sci 2005;46:1256-1263. 
27. Udar N, Atilano SR, Brown DJ, Holguin B, Small K, Nesburn $A B$, et al. SOD1: a candidate gene for keratoconus. Investig Ophthalmol Vis Sci 2006;47:3345-3351.

28. Udar N, Atilano SR, Small K, Nesburn AB, Kenney MC. SOD1 haplotypes in familial keratoconus. Cornea 2009;28:902-907.

29. Moschos MM, Kokolakis N, Gazouli M, Chatziralli IP, Droutsas D, Anagnou NP, et al. Polymorphism analysis of VSX1 and SOD1 genes in Greek patients with keratoconus. Ophthalmic Genet 2013;36:213-217.

30. De Bonis P, Laborante A, Pizzicoli C, Stallone R, Barbano $\mathrm{R}$, Longo $\mathrm{C}$, et al. Mutational screening of VSX1, SPARC, SOD1, LOX, and TIMP3 in keratoconus. Mol Vision 2011;1:2482-2494.

31. Canizales L, Rodriguez L, Rivera C, Martinez A, Mendez F, Castillo A. Low-level expression of SOD1 in peripheral blood samples of patients diagnosed with primary openangle glaucoma. Biomark Med 2016;10:1219-1223.

32. Loukovitis E, Sfakianakis K, Syrmakesi P. Genetic aspects of keratoconus: a literature review exploring potential genetic contributions and possible genetic relationships with comorbidities. Ophthalmol Ther 2018;7:263-292.

33. Panahi Y, Azimi A, Naderi M, Jadidi K, Sahebkar A. An analytical enrichment-based review of structural genetic studies on keratoconus. J Cell Biochem 2018;9:1-9.

34. Valgaeren H, Koppen C, Van Camp G. A new perspective on the genetics of keratoconus: why have we not been more successful? Ophthalmic Genet 2018;39:158-174.

35. Silva D, Gadelha B, Feitosa A, Silva R, Albuquerque T, SAntos D, et al. Analysis of VSX1 variations in Brazilian subjects with keratoconus. J Ophthalmic Vis Res 2018;13:266-273.

36. Saee-Rad S, Hashemi H, Miraftab M, Noori-Daloii MR, Chaleshtori $\mathrm{MH}$, Raoofian R, et al. Mutation analysis of VSX1 and SOD1 in Iranian patients with keratoconus. Mol Vis 2011;17:3128-3136.
37. Kumar P, Henikoff S, Ng PC. Predicting the effects of coding non-synonymous variants on protein function using the SIFT algorithm. Nat Protoc 2009;4:1073-1081.

38. Ferrer-Costa C, Gelpí JL, Zamakola L, Parraga I, de la Cruz $X$, Orozco M. PMUT: a web-based tool for the annotation of pathological mutations on proteins. Bioinformatics 2005;21:3176-3178.

39. Zeschau A, Balestrin IG, Stock RA, Bonamigo EL. Indications of keratoplasty: a retrospective study in a University Hospital. Brazilian J Ophthalmol 2013;72:316-320.

40. Almeida HG, Hida RY, Kara-Junior N. Trends in corneal transplantation from 2001 to 2016 in Brazil. Arq Bras Oftalmol 2018;81:3-6.

41. Ingre C, Wuolikainen A, Marklund SL, Birve A, Press R, Andersen PM. A 50 bp deletion in the SOD1 promoter lowers enzyme expression but is not associated with ALS in Sweden. Amyotroph Lateral Scler Front Degener 2016;17:452-457.

42. Saify K, Saadat M. Influence of a $50 \mathrm{bp}$ Ins/Del polymorphism at promoter of the superoxide dismutase-1 on gene expression and risk of heroin dependency. Environ Health Prev Med 2017;22:4-9.

43. Abu-Amero KK, Al-Muammar AM, Kondkar AA. Genetics of keratoconus: where do we stand? J Ophthalmol 2014;1-11.

44. Hao XD, Chen ZL, Qu ML, Zhao XW, Li SX, Chen PC. Decreased integrity, content, and increased transcript level of mitochondrial DNA are associated with keratoconus. PLOS ONE 2016;11:1-14.

45. Nita M, Grzybowski A. The role of the reactive oxygen species and oxidative stress in the pathomechanism of the age-related ocular diseases and other pathologies of the anterior and posterior eye segments in adults. Oxid Med Cell Longev 2016;2016. 